\title{
In vitro phagocytosis and survival of Streptococcus suis capsular type 2 inside murine macrophages
}

\author{
C. Brazeau, M. Gottschalk, S. Vincelette and B. Martineau-Doizé
}

Author for correspondence: B. Martineau-Doizé. Tel: +1 5147738521 ext. 8359. Fax: +1 5147788108 e-mail: doizeb@ere.umontreal.ca

Groupe de Recherche sur les Maladies Infectieuses du Porc, Faculté de Médecine Vétérinaire, Université de Montréal, Saint-Hyacinthe, Québec, Canada J2S 7C6
In this study, data on phagocytosis of Streptococcus suis and its survival inside macrophages are presented. Mouse peritoneal macrophages were incubated in the presence of one of five different strains of $S$. suis capsular type 2: a virulent wild-type strain (1591), a non-capsulated non-virulent mutant strain (M2), a poorly capsulated non-virulent mutant strain (M42), a non-virulent capsulated strain (1330), and the wild-type reference (virulent) strain 5735. Opsonized or non-opsonized bacteria were incubated with macrophages in vitro and samples were obtained after 1 and $3 \mathrm{~h}$ incubation. Phagocytosis as well as live and dead intracellular organisms were determined by acridine orange and crystal violet staining. After $1 \mathrm{~h}$ incubation, non-opsonized virulent and non-virulent capsulated bacteria were poorly phagocytosed (by less than $7 \%$ of the macrophages), whereas the non-capsulated non-virulent mutant strain was highly phagocytosed (by more than $68 \%$ of the macrophages). The M42 mutant strain was more phagocytosed than the capsulated strains but less than the non-capsulated M2 mutant strain (35\%). In contrast, a higher percentage of live bacteria was observed inside macrophages for the capsulated strains (1591 and 5735) than for the non- or poorly capsulated mutant strains (M2 and M42). Opsonization of bacteria with rabbit serum or heat-inactivated rabbit serum significantly increased phagocytosis. For every opsonized strain, after $3 \mathrm{~h}$ incubation, the percentage of live bacteria within macrophages was considerably lower than the corresponding non-opsonized strains. In conclusion, the capsule of $S$. suis type 2 appears to act as an important anti-phagocytic factor. However, virulent capsulated non-opsonized strains can be phagocytosed by mouse peritoneal macrophages within which they appear to survive for at least $3 \mathrm{~h}$. Serum factors other than complement increase not only phagocytosis but also intracellular killing of $S$. suis of both capsulated and non-capsulated strains.

Keywords: Streptococcus suis, capsule, opsonization, phagocytosis, intracellular survival

\section{INTRODUCTION}

Streptococcus suis is responsible for a wide range of infections in swine, such as meningitis, septicaemia, arthritis, pericarditis, endocarditis, polyserositis and pneumonia (Higgins et al., 1992; Alexander, 1991). In addition, other animal species (Devriese et al., 1990) as well as humans (Arends \& Zanen, 1988) can be affected.

Abbreviations: $A O$, acridine orange; $C V$, crystal violet; HBSS, Hanks' Balanced Salt Solution; TEM, transmission electron microscopy.
S. suis shares antigens with Lancefield group D streptococci but appears to be genetically different (Kilpper-Balz \& Schleifer, 1987). So far, 35 capsular types have been described (Gottschalk et al., 1989, 1991a; Higgins et al., 1995); among them, the capsular type 2 is the most frequently isolated from diseased pigs and humans (Arends \& Zanen, 1988; Higgins et al., 1992).

Attempts to control the infection caused by $S$. suis capsular type 2 in the field by vaccination have given equivocal results, partially due to the lack of knowledge on bacterial virulence factors. Different bacterial structures, such as 
capsule, fimbriae, haemagglutinins, extracellular and cell wall-associated proteins and haemolysin have been suggested as virulence factors (Gottschalk et al., 1990, 1992, 1995; Vecht et al., 1991; Jacobs et al., 1994). The capsule is recognized as an important component for successful invasion and disease production by many bacterial pathogens (Rubens et al., 1987). The capsular polysaccharide of $S$. suis serotype 2 is composed of five sugars, including sialic acid, and has a molecular mass of $100 \mathrm{kDa}$ (Elliott \& Taï, 1978). Although capsular sialic acid plays a well-recognized role in the resistance to phagocytosis in group B streptococci, as demonstrated by the study of asialo mutants (Rubens et al., 1987), similar functions in $S$. suis infections have not yet been studied. It has been reported that isolates of $S$. suis from diseased animals possess a thicker capsule than those isolated from healthy animals (Gottschalk et al., 1991b). In addition, an increased thickness of the capsule and an increased resistance to killing by swine polymorphonuclear neutrophils was noted for virulent strains, but not for nonvirulent strains, after being cultured in vivo (Quessy et al., 1994). It is not known whether this resistance was due to a reduced phagocytosis rate.

In contrast, Williams (1990) reported that both virulent and non-virulent capsulated isolates were readily phagocytosed by murine macrophages, but only virulent strains survived within phagosomes. Since in this study he compared capsulated virulent and non-virulent strains, the role of capsulation in phagocytosis and intracellular survival of $S$. suis could not be examined. Consequently, it was proposed that $S$. suis enters into circulation from the tonsils, is taken up by monocytes and transported to the cerebrospinal fluid via the choroid plexus (Williams \& Blakemore 1990a-c).

To study the role of the capsule of $S$. suis in pathogenicity we examined the phagocytosis and intracellular survival of capsulated and non-capsulated $S$. suis capsular type 2 strains by murine macrophages.

\section{METHODS}

Bacterial strains. Five strains of $S$. suis capsular type 2 were used. The reference strain S735 (NCTC 10234) was kindly provided by Dr Robert Higgins, University of Montreal, Canada. This strain is virulent and highly capsulated (Jacques et al., 1990; Quessy et al., 1995), and was first isolated from a diseased pig in The Netherlands. Wild-type strain 89-1591, which is also virulent and highly capsulated, was originally isolated from a case of septicaemia and meningitis in a pig. Strains M2 and M42 are spontaneous mutants derived from strain 1591 (Gottschalk et al., 1992). Strain M2 is non-virulent and non-capsulated and strain M42 is non-virulent and partially capsulated. Finally, a capsulated non-virulent strain (1330) (Quessy et al., 1995), which was isolated from the lungs of a diseased pig, was also included in this study. All isolates were cultured on $5 \%(\mathrm{v} / \mathrm{v})$ bovine blood agar plates at $37^{\circ} \mathrm{C}$ for $18 \mathrm{~h}$. From this culture, four colonies were inoculated into $5 \mathrm{ml}$ Todd-Hewitt broth (THB) (Difco Laboratories) and incubated at $37^{\circ} \mathrm{C}$ for $18 \mathrm{~h}$. Fifty microlitres of this broth was used to inoculate $5 \mathrm{ml}$ fresh THB and culturing was by incubation at $37^{\circ} \mathrm{C}$ for $5-6 \mathrm{~h}$ with agitation. The cells were harvested by centrifugation at $3000 \mathrm{~g}$ for $10 \mathrm{~min}$ and resuspended in $5 \mathrm{ml}$ RPMI 1640 (Gibco BRL) medium with glutamine and $25 \mathrm{mM}$ HEPES, lacking sodium bicarbonate. The final concentration was adjusted to $\mathrm{OD}_{540} 0.03$ (Titertek Multiskan; Flow Laboratories), which corresponds to approximately $5 \times 10^{6}$ c.f.u. $\mathrm{ml}^{-1}$.

For opsonization studies, inactivated or non-inactivated nonimmune fresh rabbit serum $(20 \%, \mathrm{v} / \mathrm{v})$ was added to the bacterial suspension and the whole mixture was rotary shaken for $30 \mathrm{~min}$ at $37^{\circ} \mathrm{C}$. Inactivation of serum was carried out at $57^{\circ} \mathrm{C}$ for $30 \mathrm{~min}$.

Preparation of macrophages. Elicited murine macrophages were obtained using standard procedures (Adams et al., 1981). Briefly, five or six, 6-8-week-old CF1 male mice (Charles Rivers) were used per individual assay. Mice were inoculated intraperitoneally with $1.5 \mathrm{ml} 3 \%(\mathrm{w} / \mathrm{v})$ thioglycolate sterile broth (Sigma). Macrophages were recovered $4 \mathrm{~d}$ later by washing the peritoneal cavity with $5.0 \mathrm{ml}$ Hanks' Balanced Salt Solution (HBSS) $\mathrm{Ca}^{2+}-, \mathrm{Mg}^{2+}$-free; Gibco). They were pooled, pelleted by centrifugation at $1000 \mathrm{~g}$ for $10 \mathrm{~min}$ and resuspended in $5.0 \mathrm{ml}$ culture medium (RPMI 1640 with glutamine and $25 \mathrm{mM}$ HEPES, lacking sodium bicarbonate) supplemented with $10 \%$ heat-inactivated foetal calf serum (Gibco) prewarmed to $37^{\circ} \mathrm{C}$. The concentration was adjusted to $0.5 \times 10^{6}$ cells $\mathrm{ml}^{-1}$ and $1.0 \mathrm{ml}$ of this macrophage suspension was placed per well of a tissue culture plate of 24 wells containing $13 \mathrm{~mm}$ circular glass coverslips and incubated in a humid atmosphere for $45 \mathrm{~min}$ at $37^{\circ} \mathrm{C}$ in $5 \%(\mathrm{v} / \mathrm{v}) \mathrm{CO}_{2}$. Non-adherent cells were removed by three washings with HBSS. To evaluate the proportion of the macrophages harvested, a non-specific esterase staining was performed according to the method of Koski et al. (1976).

Phagocytosis assay. Two isolates were tested in triplicate per individual assay, and each isolate was tested at least twice. In each assay, three coverslips were placed in wells, covered with $1.0 \mathrm{ml}$ bacterial suspension to obtain a ratio of about 10 bacterial cells per macrophage, and incubated for $60 \mathrm{~min}$ in humid atmosphere at $37^{\circ} \mathrm{C}$, in $5 \%(\mathrm{v} / \mathrm{v}) \mathrm{CO}_{2}$. Coverslips were washed five times with $\mathrm{HBSS}$ to remove the extracellular non-adherent bacteria. To evaluate the percentage of phagocytosis and the phagocytosis capacity (see below), some coverslips were stained after $1 \mathrm{~h}$ incubation. The three coverslips were stained with acridine orange (AO; Sigma) $\left(0 \cdot 144 \mathrm{mg} \mathrm{ml}^{-1}\right.$ in HBSS, $\left.\mathrm{pH} 7 \cdot 2\right)$ for $45 \mathrm{~s}$, washed twice, stained with crystal violet (CV; Sigma) $\left(0.50 \mathrm{mg} \mathrm{ml}^{-1}\right.$ in $\left.0.15 \mathrm{M} \mathrm{NaCl}, \mathrm{pH} 7.2\right)$ for $45 \mathrm{~s}$, washed twice and rinsed with a $3 \%(\mathrm{w} / \mathrm{v})$ gelatin solution. To evaluate intracellular survival, after the $60 \mathrm{~min}$ incubation, extracellular bacteria were killed with $0.45 \mu \mathrm{g}$ penicillin $\mathrm{G} \mathrm{ml} \mathrm{ml}^{-1}$ which corresponds to 15-times the MIC for the strains tested in this study (Hand \& King-Thompson, 1986). The coverslips were then incubated for a further $2 \mathrm{~h}$.

Coverslips were observed under oil at a magnification of $\times 1000$ using a Leitz microscope with a mercury lamp source with a $450-490 \mathrm{~nm}$ excitation filter. The proportion of cells containing ingested bacteria (percentage of phagocytosis) was recorded from 200 macrophages after $1 \mathrm{~h}$ incubation. The number of phagocytosed bacteria per macrophage (phagocytosis capacity) was recorded in 30 macrophages containing ingested bacteria after 1 and $3 \mathrm{~h}$ incubation. Distinction was made between live (green fluorescence) and dead bacteria (red fluorescence). To evaluate the intracellular survival, an $\mathrm{AO}-\mathrm{CV}$ stain was used. Vital staining with $A O$ is a very sensitive method for detecting ingested bacteria and also allows differentiation between live and dead intracellular bacteria since dead bacteria fluoresce red (metachromasy) and live bacteria fluoresce green or light yellow (orthochromasy). CV staining quenches the fluorescence of 
extracellular bacteria, while the fluorescence of intracellular bacteria remains unaffected. Observation and quantification of live and dead bacteria were always done by the same person. Green or light yellow bacteria were considered as live bacteria, while red, orange and orange-yellow bacteria were recorded as being dead. The results were displayed as a ratio of the total number of live bacteria to the total number of dead bacteria.

Transmission electron microscopy (TEM). For TEM studies, plastic coverslips were used instead of glass coverslips. At the end of the phagocytosis assay, the cells adherent to the coverslips were fixed with $2.5 \%(\mathrm{v} / \mathrm{v})$ glutaraldehyde in HBSS buffer, $\mathrm{pH}$ $7 \cdot 0$ for $1 \mathrm{~h}$, and post-fixed with $1 \%(\mathrm{w} / \mathrm{v}$ ) osmium tetroxide for 45 min. Dehydration was performed in a graded ethanol series and the coverslips were embedded in Spurr. Silver interferencecolour sections were collected over copper grids coated with Formvar, and post-stained with silver nitrate and lead citrate. Sections were examined and photographed with a Philips 101 transmission electron microscope operating at $80 \mathrm{kV}$.

Statistical analysis. The Fischer test was performed for the percentage of phagocytosis and the phagocytic capacity. For survival of bacteria inside macrophages the Wilk's Lambda test was performed. This test is a multivariate analysis of variance to simultaneously test two series of data (the numbers of live and dead bacteria).

\section{RESULTS}

\section{Phagocytosis of S. suis}

The percentage of macrophages in the harvesting of peritoneal cells was $97 \%$. Elicited mouse peritoneal macrophages cultured in the presence of different strains of $S$. suis capsular type 2 for $1 \mathrm{~h}$ were able to phagocytose the bacteria (Table 1). The number of macrophages which contained ingested bacteria varied according to the strain and to opsonization of the bacteria. In the absence of opsonization, the number of macrophages which ingested capsulated S. suis $(1330,1591$, S735) was significantly lower $(P<0.0001)$ than that containing the noncapsulated (M2) and the poorly capsulated (M42) strains

Table 1. Phagocytosis of $S$. suis serotype 2 by mouse peritoneal macrophages after $1 \mathrm{~h}$

\begin{tabular}{|lccc|}
\hline Strain* & \multicolumn{3}{c|}{$\begin{array}{c}\text { No. of macrophages which phagocytose } \\
\text { bacteria } \dagger\end{array}$} \\
\cline { 2 - 4 } & Non-opsonized & $\begin{array}{c}\text { Opsonized } \\
\text { with non- } \\
\text { inactivated } \\
\text { serum }\end{array}$ & $\begin{array}{c}\text { Opsonized } \\
\text { with heat- } \\
\text { inactivated } \\
\text { serum }\end{array}$ \\
& & $34 \pm 5$ & $24 \pm 11$ \\
1591 & $14 \pm 4 \ddagger$ & $35 \pm 12$ & $29 \pm 7$ \\
S735 & $14 \pm 7$ & $29 \pm 2$ & $23 \pm 4$ \\
1330 & $11 \pm 3$ & $167 \pm 21$ & $171 \pm 25$ \\
M2 & $136 \pm 12$ & $105 \pm 3$ & $105 \pm 9$ \\
M42 & $71 \pm 23$ & -3 & \\
\hline
\end{tabular}

* 1591 and S735, virulent capsulated strains; 1330, non-virulent capsulated strain; M2, non-virulent non-capsulated mutant of 1591; M42, non-virulent partially capsulated mutant of 1591 .

t A total of 200 macrophages was observed.

$\ddagger$ Mean of at least three separate experiments \pm sD.
(Table 1). Only a small number of macrophages was able to ingest the virulent and non-virulent highly capsulated strain. Indeed, $5.5 \%$ of the macrophages ingested the capsulated non-virulent (1330) strain, while $7 \%$ of the macrophages ingested each of the capsulated virulent strains (1591, S735). The number of macrophages phagocytosing the partially capsulated strain (M42) was higher than the capsulated strains, but lower than the noncapsulated strains $(P<0 \cdot 0001)$. After $3 \mathrm{~h}$ incubation, the percentage of macrophages containing intracellular $S$. suis was similar to that after $1 \mathrm{~h}$ incubation.

Opsonization increased the phagocytosis of all the strains (Table 1). As was the case for non-opsonized bacteria, no difference was observed between capsulated virulent and capsulated non-virulent strains. From the Fischer test used to analyse the percentage of phagocytosis and the phagocytic capacity, it appeared that all the strains behaved in a similar way according to opsonization with fresh serum or with heat-inactivated serum. In other words, there was an increase of the percentage of phagocytosis and phagocytic capacity with opsonization (with fresh and heat-inactivated serum), but this increase was similar for every strain $(P>0 \cdot 01)$. The less capsulated and the non-capsulated strains were phagocytosed by higher numbers of macrophages. Elimination of the complement in the serum by heating did not affect the phagocytosis of any strains as compared with the phagocytosis of strains opsonized with fresh serum.

\section{Phagocytic capacity}

Since the numbers of bacteria (strains 1330, 1591, S735) present inside individual macrophages was low, the number of ingested bacteria was recorded per 30 macrophages which showed ingested bacteria after 1 and $3 \mathrm{~h}$ incubation (Figs 1 and 2). For both incubation delays, the phagocytic capacity was significantly higher for the noncapsulated and partially capsulated mutants than for the capsulated virulent and capsulated non-virulent strains $(P$ $<0.0001)$, and this independently of the opsonization treatment. No significant difference $(P<0.0001)$ was observed between the capsulated virulent and capsulated non-virulent strains. Although the numbers of ingested M2 isolates seem to be greater after $3 \mathrm{~h}$ than after $1 \mathrm{~h}$ incubation, these differences were not significant (they were due to some counting difficulties of the intracellular bacteria resulting in high standard deviations). Indeed, especially for M2 isolates, the numbers of intracellular bacteria were very high (more than 30 bacteria per macrophage) and they tended to form clusters within the cytoplasm rendering differentiation of individual bacteria difficult.

The ratios of live to dead bacteria per 30 macrophages with ingested micro-organisms after 1 and $3 \mathrm{~h}$ incubation were compared (Table 2). These numbers were different according to the virulence and according to opsonization. In the absence of any opsonization, the ratio of live to dead bacteria for virulent strains which were ingested in macrophages after $1 \mathrm{~h}$ incubation was increased after an additional $2 \mathrm{~h}$ incubation period $(P<0.0001$; calculated 

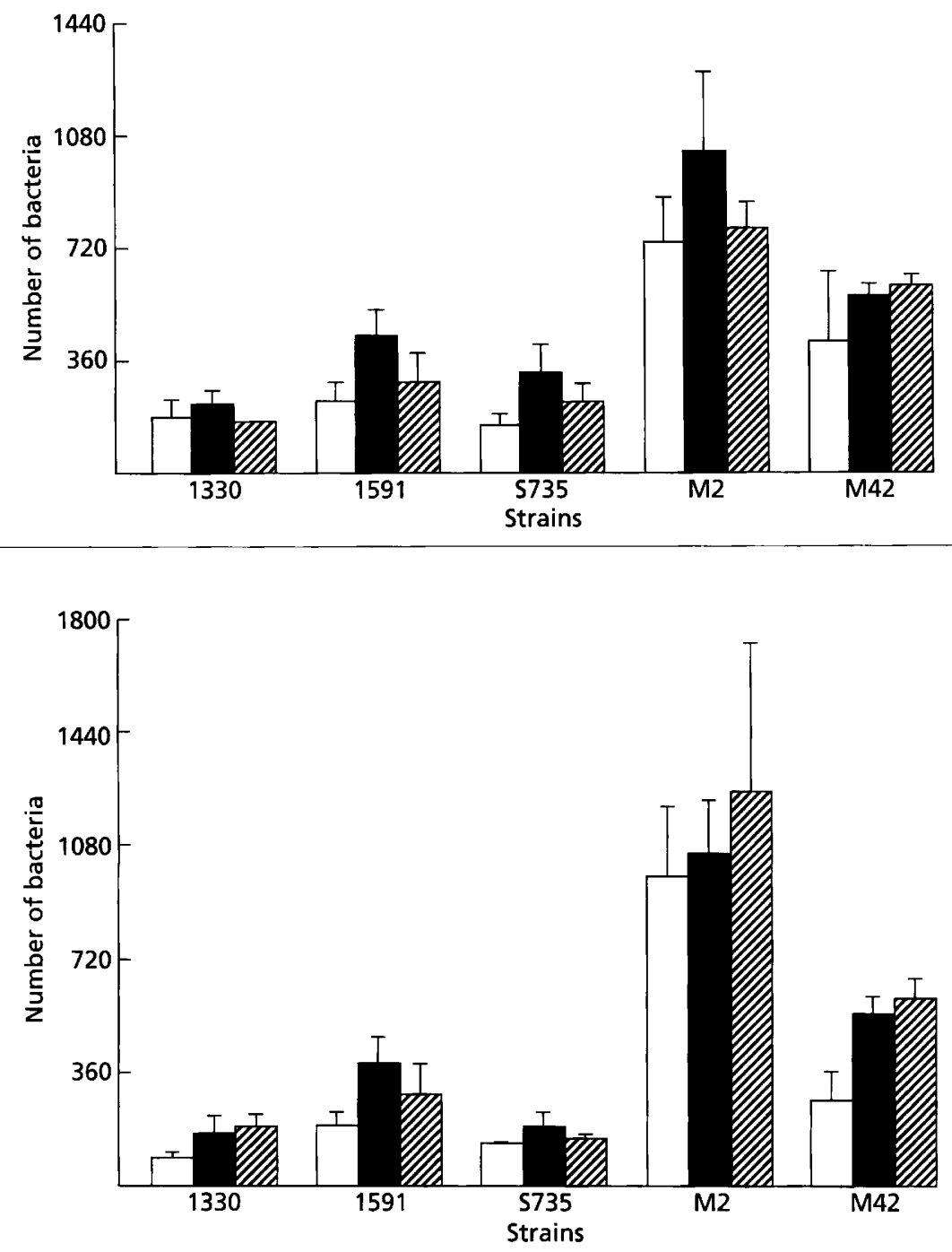

Fig. 1. Number of $S$. suis capsular type 2 phagocytosed within 30 macrophages after $1 \mathrm{~h}$ incubation. Details of strains are given in the footnotes to Table 1. Data are means of three to six experiments: vertical bars represent standard deviation. $\square$, Nonopsonized; $\square$, opsonized with non-

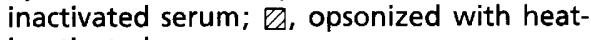
inactivated serum. with unrefined data). For the non-virulent strains, the situation was different, the ratio of live to dead bacteria inside macrophages decreased but to a lesser extent for the capsulated non-virulent strain (1330) than the non- or poorly capsulated mutants strains (M2, M42).

After opsonization with fresh or heat-inactivated serum the ratio of live to dead bacteria within the macrophages decreased with the prolongation of the incubation period for all the strains (Table 2). Thus opsonization diminishes intracellular survival for all the strains. However, the ratio for strain S735 was considerably higher than for the other capsulated strains after $1 \mathrm{~h}$ incubation.

\section{Location of S. suis within the macrophages}

Observation of thin sections by TEM revealed that $S$. suis was located within membrane-bound vesicles in the macrophage cytoplasm (Fig. 3). Since these vesicles had a clear content, they were considered as being phagosomelike vesicles. No morphological differences could be observed between virulent micro-organisms phagocytosed for 1 or $3 \mathrm{~h}$. Replication of virulent microorganisms was observed after 1 or $3 \mathrm{~h}$ incubation (Fig. 3b). Strains M2 and M42 demonstrated evident degradation of the cell wall after $3 \mathrm{~h}$ incubation (Fig. $3 \mathrm{~d}$ ). The membrane of the phagosomes containing non-virulent M2, M42 and 1330 strains was closely apposed to the micro-organisms (Fig. 3c,d), while a space could be observed between the phagosome membrane and the virulent strain S735 (Fig. 3a, b).

\section{DISCUSSION}

Capsule is recognized as an important component for successful host invasion and disease production by bacterial pathogens (Rubens et al., 1987). One of the best known mechanisms by which capsules protect bacteria is impairing their interaction with phagocytic cells. Since $S$. suis possesses a well-developed polysaccharidic capsule which, in addition, is rich in sialic acid (an antiphagocytic factor) (Elliott \& Tao, 1978), a natural resistance to phagocytosis, in the absence of specific antibodies, would be logical. However, Williams (1990) reported in an in vitro study, that well-capsulated non-pathogenic and pathogenic strains of $S$. suis were phagocytosed equally by macrophages in the absence of antibodies and/or comp- 
Table 2. Persistence of live $S$. suis serotype 2 within macrophages after 1 and $3 \mathrm{~h}$ incubation

\begin{tabular}{|c|c|c|c|c|c|c|}
\hline \multirow[t]{3}{*}{ Strain* } & \multicolumn{6}{|c|}{ Ratio of live/dead bacteria $\dagger$} \\
\hline & \multicolumn{2}{|c|}{$\begin{array}{c}\text { Non- } \\
\text { opsonized }\end{array}$} & \multicolumn{2}{|c|}{$\begin{array}{l}\text { Opsonized } \\
\text { with } \\
\text { fresh serum }\end{array}$} & \multicolumn{2}{|c|}{$\begin{array}{l}\text { Opsonized } \\
\text { with } \\
\text { heat- } \\
\text { inactivated } \\
\text { serum }\end{array}$} \\
\hline & $1 \mathrm{~h}$ & $3 \mathbf{h}$ & $1 \mathrm{~h}$ & $3 \mathrm{~h}$ & $1 \mathrm{~h}$ & $3 \mathbf{h}$ \\
\hline 1330 & $0 \cdot 31$ & $0 \cdot 16$ & $0 \cdot 30$ & $0 \cdot 10$ & $0 \cdot 36$ & $0 \cdot 16$ \\
\hline 1591 & $0 \cdot 41$ & 0.53 & $0 \cdot 41$ & $0 \cdot 15$ & $0 \cdot 38$ & 0.14 \\
\hline S735 & 0.57 & 0.96 & $2 \cdot 99$ & $0 \cdot 60$ & $1 \cdot 83$ & 0.64 \\
\hline M2 & $0 \cdot 14$ & 0.05 & 0.56 & $0 \cdot 08$ & $0 \cdot 31$ & 0.06 \\
\hline M42 & $0 \cdot 12$ & 0.03 & 0.08 & $0 \cdot 03$ & $0 \cdot 13$ & 0.06 \\
\hline
\end{tabular}

* See footnotes to Table 1 for strain characteristics.

†In 30 macrophages which have phagocytosed bacteria.

lement. The phagocytosed non-pathogenic strains did not survive whereas phagocytosed, pathogenic strains survived and could even grow intracellularly. From these observations and from in vivo studies in pigs, Williams \& Blakemore $(1990 \mathrm{a}-\mathrm{c})$ postulated that, although both polymorphonuclear and macrophage cells are capable of phagocytosing pathogenic $S$. suis in pigs lacking anti-S. suis antibodies, only pathogenic bacteria could survive and multiply inside macrophages.

The present study confirms the results presented by Williams (1990), since well-capsulated bacteria were phagocytosed by less than $10 \%$ of macrophages in the absence of antibody and/or complement in similar rates independently of their virulence capacity. However, the non-capsulated and the poorly capsulated strains were significantly more phagocytosed than the well-capsulated strain. This suggests that the capsule plays an antiphagocytic role in $S$. suis and confirms the observation of Williams (1989) that a partially capsulated mutant is more phagocytosed by macrophages than capsulated isolates. Since in our experiment the non-capsulated and poorly capsulated strains were spontaneous mutants, other unknown factors could eventually also play a role. Similar observations were recently made by Wibawan \& Lammler (1994) who indicated that a non-capsulated strain of $S$. suis capsular type 1, either opsonized or non-opsonized, was phagocytosed to a greater degree than the capsulated strain.

Although the presence of complement improves phagocytosis of many bacteria (Horstman, 1992), in the present study complement did not have a significant influence on phagocytosis of $S$. suis. However, serum factors other than complement increased the ingestion and decreased the intracellular survival of $S$. suis within macrophages. Wibawan \& Lammler (1994) had also observed an increase in phagocytosis when capsulated or noncapsulated strains were opsonized before phagocytosis.
Interestingly, there are some reports indicating that complement does not seem to play an important role in phagocytosis of group B and A streptococci (Shigeoka $e t$ al., 1983; Wagner $e$ t al., 1986). Indeed, S. Quessy and coworkers (personal communication) have identified and partially characterized an albumin-binding protein of S. suis. They also observed an increase in phagocytosis rate after treatment of $S$. suis with albumin. According to Wagner et al. (1986), plasma-protein binding may be involved in the pathogenesis of group A streptococcal infections. Interestingly, the virulence of $S$. suis capsular type 2 strains increased significantly when the bacterial inoculum was grown in $10 \%$ unactivated bovine serum (Beaudoin et al., 1992).

Williams (1990) observed that non-pathogenic capsulated isolates were killed whereas intracellular capsulated pathogenic organisms survived and replicated within phagosomes in the absence of anti-S. suis type 2 antibody and complement. In this study, we partially confirmed these results since virulent, but not non-virulent non-opsonized strains could survive inside macrophages. When normal serum, inactivated or non-inactivated, was used for opsonization, neither virulent nor non-virulent strains were able to survive inside macrophages. These results differ from those of Williams (1990), who indicated that the hyperimmune rabbit serum, but not normal serum, against $S$. suis capsular type 2 increased intracellular killing of bacteria. However, in that study, sera were added after the phagocytosis took place.

The ratio of live to dead organisms was lower in our study than that reported by Williams (1990). Using Diff-Quick staining, we observed the remaining extracellular bacteria which could not be eliminated by washings (data not shown). Ingestion of these extracellular bacteria could probably influence these ratios. To avoid this effect, we added a high concentration of penicillin $G$, to which the strains of $S$. suis used in this study were highly susceptible. It has been previously demonstrated that this antibiotic does not have any activity inside macrophages during the $3 \mathrm{~h}$ incubation period (Hand \& King-Thompson, 1986; Renard et al., 1987). Under these conditions, we observed no visible extracellular bacteria (data not shown).

Several intracellular facultative or obligatory parasites are able to survive inside macrophages or monocytes, using different strategies (Goren, 1977; Horwitz, 1988; Kaufmann \& Reddehase, 1989). The mechanism by which virulent capsulated strains of $S$. suis type 2 survive for $3 \mathrm{~h}$ within phagosomes remains unknown. This intracellular survival does not seems to be due to superoxidase dismutase synthesis (Langford et al., 1991).

Circulating monocytes containing bacteria-size particles migrate into the cerebro-spinal fluid compartment (Williams \& Blakemore, 1990c). It has been shown that after intravenous inoculation of pigs with pathogenic $S$. suis type 2 , circulating monocytes contain intracellular bacteria. In fact, it is generally accepted that in the pathogenesis of $S$. suis meningitis bacteria enter into the cerebrospinal fluid compartment in association with monocytes. However, Williams \& Blakemore (1990c) 



Fig. 3. Thin sections of murine macrophages containing S. suis capsular type 2. (a) and (b) Virulent capsulated strain after $1 \mathrm{~h}$ incubation; (c) non-virulent partially capsulated strain M42 after $3 \mathrm{~h}$ incubation; (d) non-virulent non-capsulated strain M2 after $3 \mathrm{~h}$ incubation. Arrows indicate the phagosome membrane. (a), (c) and (d) Bars $=1 \mu \mathrm{m} ;(\mathrm{b})$ bar $=0.5 \mu \mathrm{m}$.

showed that less than $2 \%$ of the monocytes of the bacteraemic pigs contained intracellular bacterial profiles. Finally, it is important to note that, in the present study with a ratio of 10 bacteria/ 1 macrophage, more than $80 \%$ of the macrophages could not phagocytose wellopsonized capsulated $S$. suis. This may indicate that in natural infection most bacteria remain outside macrophages or monocytes. Whether these bacteria are phagocytosed and destroyed by other host cells or whether they play an active role in the pathogenesis of the infection is not known.

In conclusion, the capsule of $S$. suis type 2 acts as an important anti-phagocytic factor. However, virulent capsulated non-opsonized strains can be phagocytosed by mouse peritoneal macrophages within which they survive for at least $3 \mathrm{~h}$. Serum factors other than complement increase not only phagocytosis but also intracellular killing of S. suis.

\section{ACKNOWLEDGEMENTS}

We would like to thank Isabelle Caya for her excellent technical assistance and Ghyslain Dumas for his help in statistical analysis. C. B. was a recipient of an MSc scholarship from the Fonds pour la Formation de Chercheurs et l'Aide à la Recherche (FCAR). This work was supported by the Conseil des Recherches en Pêche et en Agro-alimentaire du Québec (CORPAQ \#3639). 


\section{REFERENCES}

Adams, D. O., Edelson, P. J. \& Koren, H. S. (1981). In Methods for Studying Mononuclear Phagocytes, pp. 63-66. New York: Academic Press.

Alexander, T. J. L. (1991). Streptococcus suis: an update. Pig Vet J 27, $50-60$.

Arends, J. P. \& Zanen, H. C. (1988). Meningitis caused by Streptococcus suis in humans. Rev Infect Dis 10, 131-137.

Beaudoin, M., Higgins, R., Harel, J. \& Gottschalk, M. (1992). Studies on a murine model for evaluation of virulence of Streptococcus suis capsular type 2 isolates. FEMS Microbiol Lett 99, 111-166.

Devriese, L. A., Sustronck, B., Maenhout, T. \& Haesebrouck, F. (1990). Streptococcus suis meningitis in a horse. Vet $\operatorname{Rec} 127,68$.

Elliott, S. D. \& Taï, J. Y. (1978). The type specific polysaccharide of Streptococcus suis. J Exp Med 148, 1699-1704.

Goren, M. B. (1977). Phagocyte lysosomes interactions with infectious agents, phagosomes, and experimental perturbations in function. Annu Rev Microbiol 31, 507-533.

Gottschalk, M., Higgins, R., Jacques, M., Mittal, M. R. \& Henrichsen, J. (1989). Description of 14 new capsular types of Streptococcus suis. J Clin Microbiol 27, 2633-2636.

Gottschalk, M., Lebrun, A., Jacques, M. \& Higgins, R. (1990). Haemagglutination properties of Streptococcus suis. J Clin Microbiol 28, 2156-2158.

Gottschalk, M., Higgins, R., Jacques, M., Beaudoin, M. \& Henrichsen, J. (1991a). Characterisation of six new capsular types (23 through 28) of Streptococcus suis. J Clin Microbiol 29, 2590-2594.

Gottschalk, M., PetitBois, S., Higgins, R. \& Jacques, M. (1991b). Adherence of Streptococcus suis capsular type 2 to porcine lungs sections. Can J Vet Res 55, 302-304.

Gottschalk, M., Higgins, R., Jacques, M. \& Dubreuil, D. (1992). Production and characterization of two Streptococcus suis capsular type 2 mutants. Vet Microbiol 30, 59-71.

Gottschalk, M. G., Lacouture, S. \& Dubreuil, J. D. (1995). Characterization of Streptococcus suis capsular type 2 haemolysin. Microbiology 141, 189-195.

Hand, W. L. \& King-Thompson, N. L. (1986). Contrasts between phagocyte antibiotic uptake and subsequent intracellular bactericidal activity. Antimicrob Agents Chemother 29, 135-140.

Higgins, R., Gottschalk, M., Beaudoin, M. \& Rawluk, S. A. (1992). Distribution of Streptococcus suis capsular types in Quebec and Western Canada. Can Vet Res 33, 27-30.

Higgins, R., Gottschalk, M., Boudreau, M., Lebrun, A. \& Henrichsen, J. (1995). Description of six new capsular types (29 through 34) of Streptococcus suis. J Vet Diagn Invest 7, 405-406.

Horstman, R. D. (1992). Target recognition failure by nonspecific defense system: surface constituents with the alternative pathway of complement activation. Infect Immun 60, 721-727.

Horwitz, M. A. (1988). Intracellular parasitism. Curr Opin Immunol 1, 41-46.

Jacobs, A. A. C., Loeffen, P. L. W., Van Den Berg, A. J. G. \& Storm, P. K. (1994). Identification, purification, and characterization of a thiol-activated haemolysin (suilysin) of Streptococcus suis. Infect Immun 62, 1742-1748.

Jacques, J., Gottschalk, M., Foiry, B. \& Higgins, R. (1990). Ultrastructural study of surface components of Streptococcus suis. J Bacteriol 172, 2833-2838.
Kaufmann, S. H. E. \& Reddehase, M. J. (1989). Infection of phagocytic cells. Curr Opin Immunol 2, 43-49.

Kilpper-Balz, R. \& Schleifer, K.-H. (1987). Streptococcus suis sp. nov., nom. rev. Int J Syst Bacteriol 37, 160-162.

Koski, K. R., Poplack, D. G. \& Blaese, R. M. (1976). A non-specific esterase stain for the identification of monocytes and macrophages. In In Vitro Methods in Cell Mediated and Tumor Immunity, pp, 359-362. Edited by B. R. Bloom \& J. R. David. New York: Academic Press.

Langford, P., Williams, A. E. \& Kroll, J. S. (1991). Superoxide dismutase of pathogenic and non-pathogenic Streptococcus suis type 2 isolates. FEMS Microbiol Lett 77, 347-350.

Quessy, S., Dubreuil, J. D., Jacques, M., Malouin, F. \& Higgins, R. (1994). Increase of capsular material thickness following in vivo growth of virulent Streptococcus suis serotype 2 strains. FEMS Microbiol Lett 115, 19-26.

Quessy, S., Dubreuil, J. D., Caya, M. \& Higgins, R. (1995). Discrimination of virulent and avirulent Streptococcus suis capsular type 2 isolates from different geographical origins. Infect Immun 63, 1975-1979.

Renard, C., Vanderhaeghe, H. J., Claes, P. J., Zenebergh, A. \& Tulkens, P. M. (1987). Influence of conversion of penicillin $G$ into a basic derivate on its accumulation and subcellular localization in cultured macrophages. Antimicrob Agents Chemother 31, 410-416.

Rubens, C. E., Wessels, M. R., Heggen, L. M. \& Kasper, D. L. (1987). Transposon mutagenesis of type III group B Streptococcus: correlation of capsule expression with virulence. Proc Natl Acad Sci US A 84, 7208-7212.

Shigeoka, A. O., Rote, N. S., Santos, J. I. \& Hill, H. R. (1983). Assessment of the virulence factors of group B streptococci: correlation with sialic acid content. J Infect Dis 147, 857-863.

Vecht, U., Wisselink, H. J., Jellema, M. L. \& Smith, H. E. (1991). Identification of two proteins associated with virulence of Streptococcus suis type 2. Infect Immun 59, 3156-3162.

Wagner, B., Schmidt, K. H., Wagner, M. \& Köhler, W. (1986). Albumin bound to the surface of $\mathrm{M}$ protein-positive streptococci increased their phagocytosis by human polymorphonuclear leukocytes in the absence of complement and bactericidal antibodies. Zentralb Bakteriol Hyg Ser A 261, 432-446.

Wibawan, I. W. T. \& Lammler, C. (1994). Relation between encapsulation and various properties of Streptococcus suis. J Vet Med $B$ 41, 453-459.

Williams, A. E. (1989). Studies on the pathogenesis of Streptococcus suis type 2 in the pig. PhD thesis, University of Cambridge.

Williams, A. E. (1990). Relationship between intracellular survival in macrophages and pathogenicity of Streptococcus suis type 2 isolates. Microb Pathog 8, 189-196.

Williams A. E. \& Blakemore, W. F. (1990a). Pathology of streptococcal meningitis following intravenous intracisternal and natural routes of infection. Neuropathol Appl Neurobiol 16, 345-356.

Williams A. E. \& Blakemore, W. F. (1990b). Monocyte-mediated entry of pathogens into the central nervous system. Neuropathol Appl Neurobiol 16, 377-392.

Williams A. E. \& Blakemore, W. F. (1990c). Pathogenesis of meningitis caused by Streptococcus suis type 2 in the pig. I Infect Dis $162,474-481$.

Received 22 June 1995; revised 10 November 1995; accepted 21 December 1995. 